\title{
Production of Titanium Dioxide Directly from Titanium Ore through Selective Chlorination Using Titanium Tetrachloride
}

\author{
Jungshin Kang ${ }^{1,2, *}$ and Toru H. Okabe ${ }^{2}$ \\ ${ }^{1}$ Department of Materials Engineering, Graduate School of Engineering, The University of Tokyo, Tokyo 113-8656, Japan \\ ${ }^{2}$ Institute of Industrial Science, The University of Tokyo, Tokyo 153-8505, Japan
}

For the production of high-grade titanium dioxide $\left(\mathrm{TiO}_{2}\right)$ directly from titanium ore (Ti ore), a fundamental study on the development of a novel carbo-selective-chlorination method using titanium tetrachloride $\left(\mathrm{TiCl}_{4}\right)$ as a chlorinating agent was carried out. In order to selectively remove iron directly from low-grade $\mathrm{Ti}$ ore $\left(\right.$ mainly $\left.\mathrm{FeTiO}_{3}\right)$, Ti ore and carbon powder were set in a gas-tight quartz tube that was then placed in a horizontal furnace to react with $\mathrm{TiCl}_{4}$ at $1100 \mathrm{~K}$. In the experiments, various types of Ti ores produced in different countries were reacted with $\mathrm{TiCl}_{4}$ for durations from 4 to $6 \mathrm{~h}$. Under certain conditions, the iron in the titanium ore was removed as iron chloride $\left(\mathrm{FeCl}_{2}\right)$, and $98 \% \mathrm{TiO}_{2}$ was obtained after the experiments. The effectiveness of $\mathrm{TiCl}_{4}$ as a chlorinating agent for the carbo-selective-chlorination of iron oxide was verified in this study. Thus, it was demonstrated that the carbo-selective-chlorination is feasible for the selective removal of iron directly from low-grade titanium ore containing $51 \% \mathrm{TiO}_{2}$ to produce high-grade $\mathrm{TiO}_{2}$ feed in a single step. [doi:10.2320/matertrans.M-M2013843]

(Received October 21, 2013; Accepted December 12, 2013; Published February 25, 2014)

Keywords: chlorination, up-grading, carbo-selective-chlorination, selective chlorination, titanium ore, titanium tetrachloride, titanium smelting, iron removal, synthetic rutile

\section{Introduction}

Titanium (Ti) is produced by the Kroll process in current industrial manufacturing. The principal procedures of the Kroll process include (i) the chlorination of a high-grade $\mathrm{TiO}_{2}$ feed by chlorine gas $\left(\mathrm{Cl}_{2}\right)$ in the presence of carbon to produce $\mathrm{TiCl}_{4}$ (the chlorination process), (ii) the reduction of $\mathrm{TiCl}_{4}$ by magnesium $(\mathrm{Mg})$ to produce Ti metal, and (iii) the electrolysis of magnesium chloride $\left(\mathrm{MgCl}_{2}\right) .{ }^{1,2)}$ There are several important issues involved in the effective operation of the Kroll process, such as increasing the efficiency of the electrolysis, controlling the heat produced by the reduction reaction, and reducing the amounts of chloride wastes produced. ${ }^{3)}$ Among these issues, one of the most important issues is the grade (or purity) of the $\mathrm{TiO}_{2}$ feed for the chlorination process.

Currently, high-grade $\mathrm{TiO}_{2}$ with a purity above $95 \%$ is used for the Ti smelting process to decrease the chlorine loss, prevent pipe clogging, and prevent damage to the refractory materials in the chlorinator. However, the use of a high-grade $\mathrm{TiO}_{2}$ feed has become more difficult nowadays, mainly because the price of high-grade $\mathrm{TiO}_{2}$ feed has increased owing to the increase in consumption of $\mathrm{TiO}_{2}$ feed in China and other developing countries. ${ }^{4)}$ In this situation, Ti metal production companies in Japan have started to investigate the usage of lower grade feed, of about $90 \% \mathrm{TiO}_{2}$ feed, instead of the $95 \% \mathrm{TiO}_{2}$ feed. ${ }^{4,5)}$

However, this approach is still in limited use owing to certain unresolved technical problems in the current production process. For example, when low-grade $\mathrm{TiO}_{2}$ feed is used in the chlorinator in the chlorination process, pipe clogging occurs as a consequence of the condensation of chlorides such as iron chlorides $\left.\left(\mathrm{FeCl}_{x},[x=2,3]\right)\right)^{3,31)}$ In addition, the generation of chloride wastes induces chlorine loss in the Kroll process, because $\mathrm{Cl}_{2}$ is recycled and circulated in the Kroll process when producing not any chloride wastes.

*Corresponding author, E-mail: jskang@iis.u-tokyo.ac.jp
Furthermore, if a low-grade $\mathrm{TiO}_{2}$ feed containing certain amount of alkaline metals or alkaline earth metals is used as a feedstock, damage to the refractory materials inside the chlorinator occurs because such metal chlorides lead to a corrosive environment at high temperatures.

Currently, high-grade $\mathrm{TiO}_{2}$ feed is produced by the Becher process, ${ }^{7,8)}$ Benilite process, ${ }^{9-11)}$ and slag process ${ }^{12}$ ) with post-treatment (the UGS process). However, these processes have drawbacks such as multiple steps for removal of iron or the production of a large amount of acid aqueous waste solution. ${ }^{3)}$ Some countries such as Japan have strict environmental regulations for the disposal and treatment of industrial wastes. Therefore, when the upgrading of low-grade Ti ore is considered in these countries, an environmentally sound process that does not produce a large amount of acid aqueous waste solution or that can recycle the wastes must be established.

Extensive studies have been carried out to improve the current processes for the effective production of high-grade $\mathrm{TiO}_{2}$ feed at reduced costs, and selective chlorination using a pyrometallurgical method has been found to be promising for upgrading low-grade $\mathrm{Ti}$ ores. ${ }^{4,6,13-26)}$ Comprehensive research was conducted on selective chlorination using a pyrometallurgical method. For example, selective chlorination of $\mathrm{Ti}$ ore by $\mathrm{Cl}_{2}$ gas in the presence of carbon ${ }^{13-16)}$ or under a $\mathrm{CO} / \mathrm{Cl}_{2}$ mixed atmosphere (carbo-chlorination) was conducted. ${ }^{17-19)}$ Recently, selective chlorination using calcium chloride $\left(\mathrm{CaCl}_{2}\right)$ or $\mathrm{MgCl}_{2}$ as a chlorinating agent has been investigated. ${ }^{20,21)}$ In addition, the authors developed a new selective chlorination process using $\mathrm{HCl}$ gas produced in the presence of $\mathrm{CaCl}_{2}$ or $\mathrm{MgCl}_{2}$ as a chlorine source, and 97\% $\mathrm{TiO}_{2}$ was obtained from a low-grade $\mathrm{Ti}$ ore containing $51 \% \mathrm{TiO}_{2}$ under certain conditions. ${ }^{4,22)}$ Although the effectiveness of selective chlorination using $\mathrm{CaCl}_{2}$ or $\mathrm{MgCl}_{2}$ was demonstrated, several technical problems regarding its practical application have remained unresolved. One such problem is the damage to the chlorinator used in the Kroll process by the condensed chlorides, such as $\mathrm{CaCl}_{2}$ or $\mathrm{MgCl}_{2}$, 
because they lead to a corrosive environment at high temperatures.

Meanwhile, among the researchers studying selective chlorination using metal chlorides in the past, ${ }^{23-26)}$ Othmer extensively investigated chlorination processes using $\mathrm{TiCl}_{4}{ }^{23-25)}$ First, Othmer researched oxidation-chlorination, where the chlorination of $\mathrm{Fe}_{2} \mathrm{O}_{3}$ by $\mathrm{TiCl}_{4}$ was claimed. Practically, this reaction is a replacement reaction of oxide(s) and chloride(s) in an oxidative atmosphere rather than an oxidation reaction. The second approach was reductionchlorination. Generally, this process is called carbochlorination. Othmer claimed that $\mathrm{Ti}$ ore containing iron oxides could be chlorinated using $\mathrm{Cl}_{2}$ gas in the presence of carbon to produce $\mathrm{TiCl}_{4}$. In addition, the chlorination of Ti ore containing $\mathrm{FeO}$ by $\mathrm{TiCl}_{4}$ in the presence of carbon was also claimed. In this process, the exhaust gas stream containing $\mathrm{TiCl}_{4}$ produced by carbo-chlorination in a reactor was directly used for chlorinating the $\mathrm{Ti}$ ore in another reactor that contains carbon. In any case, no systematic thermodynamic analysis considering the partial pressures of oxygen $\left(p_{\mathrm{O}_{2}}\right)$ and chlorine $\left(p_{\mathrm{Cl}_{2}}\right)$ was conducted.

Based on this background research, the authors conducted a fundamental study on a novel carbo-selective-chlorination method that used $\mathrm{TiCl}_{4}$ as a chlorinating agent in the presence of carbon in order to selectively remove iron from Ti ores to produce high-grade $\mathrm{TiO}_{2}$. In addition, a systematic thermodynamic analysis utilizing chemical potential diagrams was carried out to verify the mechanism of this process, which had not been done in the past.

Figure 1 shows the flow diagram for the new Ti smelting process based on carbo-selective-chlorination investigated in this study. There are several advantages of this carboselective-chlorination using $\mathrm{TiCl}_{4}$ when applied to a practical process. As shown in Fig. 1, first, because a large amount of $\mathrm{TiCl}_{4}$ is circulated in the current Ti smelting process, the carbo-selective-chlorination process can easily be adapted into the Kroll process. Second, $\mathrm{Cl}_{2}$ gas can be collected from the chloride wastes produced, because they are produced in a dry form not containing any water. ${ }^{27)}$ In addition, if this process is used for the pretreatment of lowgrade $\mathrm{TiO}_{2}$ feed, the problems with the chlorinator in the current chlorination process, such as chlorine loss and pipe clogging, can be decreased. Moreover, a large amount of acid aqueous waste solution is not generated, because no concentrated acid is necessary for removing iron from Ti ore. Furthermore, even though carbon powder is mixed with Ti ore as a feedstock for carbo-selective-chlorination, the mixture of the ore and carbon powder can be supplied directly to the current chlorination process. Finally, highgrade $\mathrm{TiO}_{2}$ feed can be obtained directly from the low-grade Ti ore in a single step.

\section{Thermodynamic Analysis of Carbo-selective- chlorination Using $\mathrm{TiCl}_{4}$}

Thermodynamically, the iron oxides and titanium oxides in the $\mathrm{Ti}$ ore can be considered to exist as a mixture of both oxides, because the Gibbs energy of formation of $\mathrm{FeTiO}_{3}$ at $1100 \mathrm{~K}$ is a small negative value, as shown in eq. (1). Therefore, the thermodynamic analysis of the mechanism of

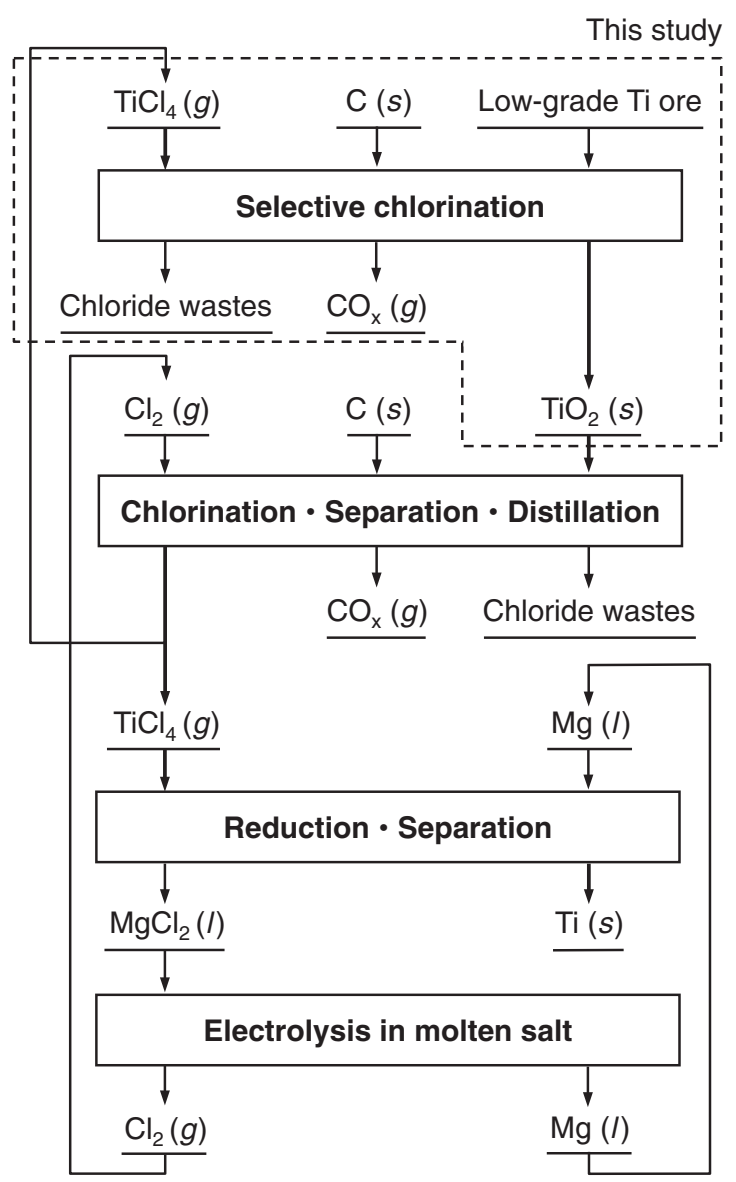

Fig. 1 Flow diagram for new titanium smelting adopting the selective chlorination process investigated in this study.

the chlorination of the Ti ore can be conducted by utilizing the chemical potential diagrams of the $\mathrm{Fe}-\mathrm{O}-\mathrm{Cl}$ and $\mathrm{Ti}-\mathrm{O}-\mathrm{Cl}$ systems at $1100 \mathrm{~K}$.

$$
\begin{gathered}
\mathrm{FeO}(s)+\mathrm{TiO}_{2}(s)=\mathrm{FeTiO}_{3}(s) \\
\Delta G^{\circ}{ }_{\mathrm{r}}=-11.0 \mathrm{~kJ} \text { at } 1100 \mathrm{~K}^{28)}
\end{gathered}
$$

Figure 2 shows the combined chemical potential diagram of the $\mathrm{Fe}-\mathrm{O}-\mathrm{Cl}$ and $\mathrm{Ti}-\mathrm{O}-\mathrm{Cl}$ systems at $1100 \mathrm{~K}$ plotted with the logarithms of $p_{\mathrm{Cl}_{2}}$ and $p_{\mathrm{O}_{2}}$ as the abscissa and ordinate, respectively. ${ }^{22)}$ By overlapping the two chemical potential diagrams, the potential region for the selective chlorination can be analyzed, and this potential region is indicated as a hatched region in Fig. 2. As shown in Fig. 2, the $\mathrm{FeCl}_{x}$ $(x=2,3)$ and the $\mathrm{TiO}_{2}$ are stable in the hatched region. Therefore, if $p_{\mathrm{Cl}_{2}}$ and $p_{\mathrm{O}_{2}}$ are located in that region, iron oxides in the $\mathrm{Ti}$ ore will be transformed to $\mathrm{FeCl}_{x}(x=2,3)$ and titanium oxides will remain as $\mathrm{TiO}_{2}(s)$. In the case of $\mathrm{FeCl}_{2}(l)$, although it is thermodynamically stable as a condensed phase at $1100 \mathrm{~K}$, its vapor pressure at $1100 \mathrm{~K}$ is $0.09 \mathrm{~atm}$, which is high enough for the $\mathrm{FeCl}_{2}(l)$ to evaporate. $^{28)}$ Therefore, if the chemical potentials of the oxygen and the chlorine are located in the selective chlorination region, the iron in the $\mathrm{Ti}$ ore can be selectively chlorinated as $\mathrm{FeCl}_{x}(l, g)(x=2,3)$, and $\mathrm{TiO}_{2}(s)$ can be obtained.

Since an excess amount of $\mathrm{TiCl}_{4}$ gas was used as a chlorinating agent in this study, the equilibrium line of the $\mathrm{TiO}_{2}(s) / \mathrm{TiCl}_{4}(g)$ eq. in Fig. 2 dominates the chlorination 
$\mathrm{Fe}-\mathrm{O}-\mathrm{Cl}$ system,

Ti-O-Cl system, $T=1100 \mathrm{~K}$

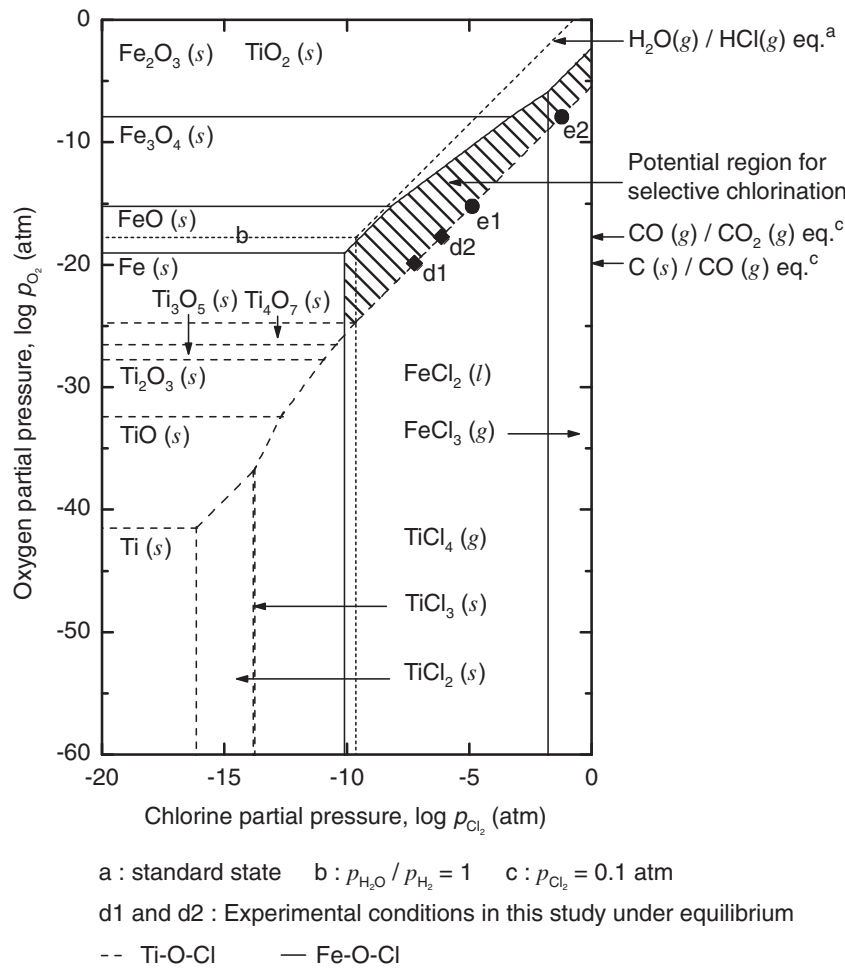

Fig. 2 Chemical potential diagrams of the $\mathrm{Fe}-\mathrm{O}-\mathrm{Cl}$ system (solid line) and the $\mathrm{Ti}-\mathrm{O}-\mathrm{Cl}$ system (dotted line) overlapped at $1100 \mathrm{~K} .^{28)}$

reactions in the reaction system. This equilibrium line passes the borderline of the potential region for selective chlorination. In addition, the oxygen chemical potential in the reaction system is controlled by the $\mathrm{C}(s) / \mathrm{CO}(g)$ eq. or the $\mathrm{CO}(g) / \mathrm{CO}_{2}(g)$ eq., because carbon was used in the reaction system. In this case, point $\mathrm{d} 1$ or $\mathrm{d} 2$ in Fig. 2 controls the chemical potentials of the reaction system. If the oxygen chemical potentials of the iron oxides in the Ti ore are considered, the $p_{\mathrm{O}_{2}}$ in the reaction system might be locally controlled by the $\mathrm{FeO}(s) / \mathrm{Fe}_{3} \mathrm{O}_{4}(s)$ eq. (point e1 in Fig. 2) or $\mathrm{Fe}_{3} \mathrm{O}_{4}(s) / \mathrm{Fe}_{2} \mathrm{O}_{3}(s)$ eq. (point e2 in Fig. 2). However, because the chlorination reaction was carried out in the presence of carbon, thermodynamically, the reaction system in this study is controlled by the conditions indicated by point d1 or $\mathrm{d} 2$ in Fig. 2.

Figure 3 shows equilibrium lines of the $\mathrm{FeO}_{x}(s) / \mathrm{FeCl}_{y}$ $(l, g)$ eq. and the $\mathrm{TiO}_{2}(s) / \mathrm{TiCl}_{4}(g)$ eq. and the potential regions for several chlorination reactions at $1100 \mathrm{~K}$. The potential region for the carbo-selective-chlorination investigated in this study is depicted as the cross-hatched region in Fig. 3. For reference, the potential regions for the oxidationselective-chlorination investigated by Othmer ${ }^{24)}$ and for the carbo-chlorination in the conventional chloride process are also shown in Fig. 3. It is worth noting that the carbochlorination process already has established applications in industry, whereas the carbo-selective-chlorination discussed here has not been applied in practical manufacturing so far.

Thermodynamically, if a large excess amount of $\mathrm{TiCl}_{4}$ and carbon exist in the reaction system and the reaction system is in the equilibrium state, the chemical potential of the carbo-

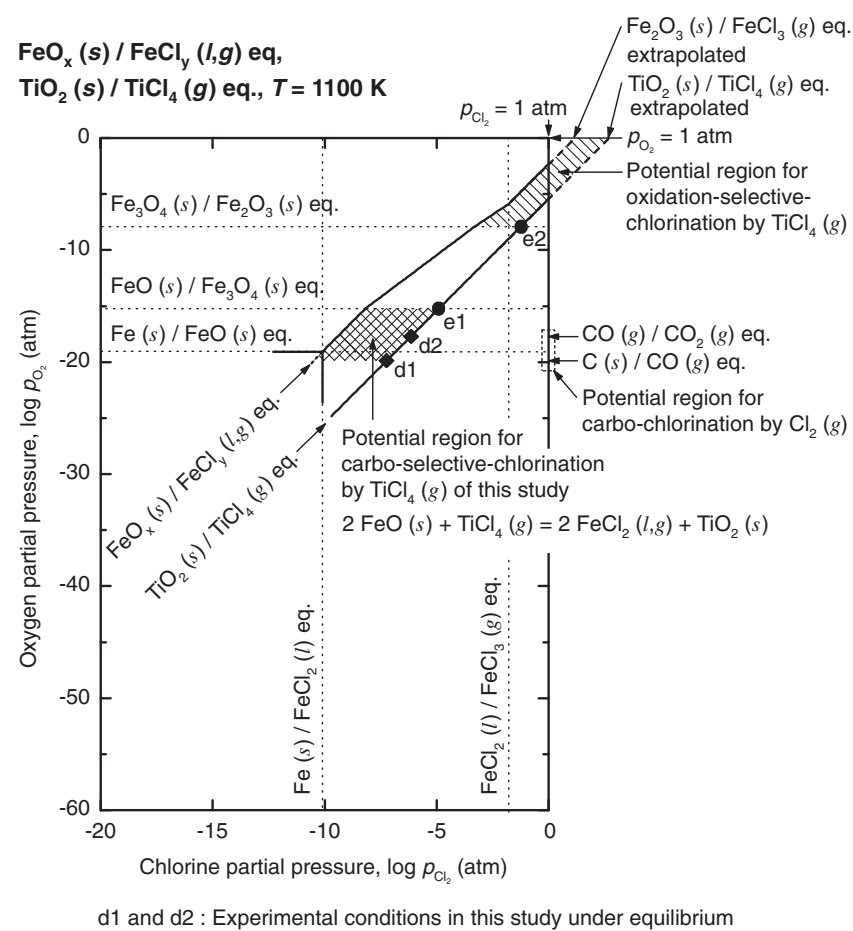

Fig. 3 Comparison of potential regions for this study, carbo-chlorination, and oxidation chlorination using the modified chemical potential diagram of the $\mathrm{Fe}-\mathrm{O}-\mathrm{Cl}$ and the $\mathrm{Ti}-\mathrm{O}-\mathrm{Cl}$ systems at $1100 \mathrm{~K} .{ }^{28)}$

selective-chlorination is fixed at point $\mathrm{d} 1$ or $\mathrm{d} 2$ in Fig. 3. However, when the redox potential of solid $\mathrm{FeO}$ in $\mathrm{Ti}$ ore is considered, the carbo-selective-chlorination works in a wider oxygen chemical potential range. In this case, the oxygen chemical potential ranges from the $\log p_{\mathrm{O}_{2}}$ value that is determined by the $\mathrm{Fe}(s) / \mathrm{FeO}(s)$ eq. to point el in Fig. 3. Therefore, when the carbon in the system and the redox potential of solid $\mathrm{FeO}$ in $\mathrm{Ti}$ ore are considered, the oxygen chemical potential ranges from point d1 to point e1 in Fig. 3. Meanwhile, when the chlorination of a Ti ore particle is considered, the outermost boundary of the ore particle reacting with $\mathrm{TiCl}_{4}$ is controlled by the $\mathrm{TiO}_{2}(s) / \mathrm{TiCl}_{4}(g)$ eq., and the center of the ore particle not yet reacting with $\mathrm{TiCl}_{4}$ is controlled by the $\mathrm{FeO}_{x}(s) / \mathrm{FeCl}_{y}(l, g)$ eq. If the chemical potential gradient between the two equilibriums is considered, the chemical potential pair of $p_{\mathrm{Cl}_{2}}$ and $p_{\mathrm{O}_{2}}$ can be placed between the equilibrium lines of the $\mathrm{FeO}_{x}(s) / \mathrm{FeCl}_{y}$ $(l, g)$ eq. and the $\mathrm{TiO}_{2}(s) / \mathrm{TiCl}_{4}(g)$ eq. As a result, the potential region between the equilibrium lines of the $\mathrm{FeO}_{x}$ $(s) / \mathrm{FeCl}_{y}(l, g)$ eq. and the $\mathrm{TiO}_{2}(s) / \mathrm{TiCl}_{4}(g)$ eq. can be identified as the potential region for the selective chlorination of iron in Ti ore. Thus, under these two conditions, the crosshatched region shown in Fig. 3 becomes the potential region for the carbo-selective-chlorination in this study.

The potential region for the carbo-selective-chlorination is located within the stability region of $\mathrm{FeCl}_{2}(l)$, and the vapor pressure of $\mathrm{FeCl}_{2}(l)$ at $1100 \mathrm{~K}$ is high enough to allow for evaporation, as mentioned before. Therefore, when $\mathrm{TiCl}_{4}$ is used as a chlorinating agent for the carbo-selectivechlorination at $1100 \mathrm{~K}$, the iron oxide in the Ti ore is removed as $\mathrm{FeCl}_{2}(l, g)$ and the $\mathrm{TiO}_{2}$ remains, according to the following overall chemical reaction. 
Table 1 Experimental conditions used in this study.

\begin{tabular}{|c|c|c|c|c|c|c|}
\hline \multirow[b]{2}{*}{ Exp. no. ${ }^{* 1}$} & \multirow{2}{*}{$\begin{array}{l}\text { Source country } \\
\text { for Ti ore }\end{array}$} & \multirow{2}{*}{$\begin{array}{l}\text { Reaction time, } \\
t_{\mathrm{r}}^{\prime} / \mathrm{h}\end{array}$} & \multirow{2}{*}{$\begin{array}{l}\text { Weight of carbon, } \\
w_{\mathrm{c}} / \mathrm{g}\end{array}$} & \multicolumn{3}{|c|}{$\mathrm{TiCl}_{4} \mathrm{feed}^{* 5}$} \\
\hline & & & & $\begin{array}{l}\text { Rate, } \\
f_{\mathrm{TiCl}_{4}} / \mathrm{g} \cdot \mathrm{min}^{-1}\end{array}$ & Feeding pattern & $\begin{array}{l}\text { Feeding time, } \\
t_{\mathrm{TiCl}_{4}}{ }^{\prime} / \mathrm{ks}\end{array}$ \\
\hline $130703^{* 3}$ & Vietnam & 6 & 0.50 & 0.164 & 2 & 9.12 \\
\hline $130704^{* 3}$ & Australia & 6 & 0.50 & 0.163 & 2 & 9.18 \\
\hline $130708^{* 3}$ & China & 6 & 0.50 & 0.167 & 2 & 9.00 \\
\hline $130730^{* 4}$ & Vietnam & 4 & 0.50 & 0.192 & 2 & 7.80 \\
\hline
\end{tabular}

${ }^{* 1}$ Experimental conditions;

Reaction temperature, $T=1100 \mathrm{~K}$.

Weight of Ti ore, $w_{\text {ore }}=2.00 \mathrm{~g}$.

Size of Ti ore used, $d_{\text {ore }}=74-149 \mu \mathrm{m}$.

${ }^{* 2}$ Ar flow rate for entire reaction time with fan, $f_{\mathrm{Ar}}=500 \mathrm{sccm}$.

${ }^{* 3}$ Ar flow rate for $5 \mathrm{~h}$ (from 0 to $5 \mathrm{~h}$ ) with fan, $f_{\mathrm{Ar}}=500 \mathrm{sccm}$.

Ar flow rate for $1 \mathrm{~h}$ (from 5 to $6 \mathrm{~h}$ ) without fan, $f_{\mathrm{Ar}}=1000 \mathrm{sccm}$.

${ }^{*} 4$ Ar flow rate for entire reaction time with fan, $f_{\mathrm{Ar}}=500 \mathrm{sccm}$.

Time for evacuation before taking out the quartz tube from furnace $=10 \mathrm{~min}$, and when evacuation was performed, exhaust gas was captured in the glass bottle cooled by liquid nitrogen.

Titanium ore was mixed with carbon.

${ }^{* 5}$ Amount of $\mathrm{TiCl}_{4}$ used, $w_{\mathrm{TiCl}_{4}}=25 \mathrm{~g}$.

$\mathrm{TiCl}_{4}$ feeding pattern 1: feeding for $30 \mathrm{~min}$ and break of feeding for $10 \mathrm{~min}$.

$\mathrm{TiCl}_{4}$ feeding pattern 2 : continuous feeding without break.

Feeding time of feeding pattern 1 includes periodic breaks.

$$
\begin{gathered}
\mathrm{FeO}(s, \text { in the ore })+1 / 2 \mathrm{TiCl}_{4}(g) \\
=\mathrm{FeCl}_{2}(l)+1 / 2 \mathrm{TiO}_{2}(s) \\
\Delta G^{\circ}{ }_{\mathrm{r}}=-69.1 \mathrm{~kJ} \text { at } 1100 \mathrm{~K}^{28)}
\end{gathered}
$$

\section{Experimental}

Figure 4 shows a schematic diagram of the experimental apparatus used in this study and a photograph of the quartz reaction tube taken before the experiment. In addition, detailed experimental conditions for this study are summarized in Table 1.

Prior to the experiments, Ti ore (see Table 2) and carbon powder (Kojundo Chemical Lab. Co., Ltd., purity $\geq 99.9 \%$ ) were placed in separate quartz crucibles (crucible for carbon: $\phi=26 \mathrm{~mm}$, I.D.; $d=24 \mathrm{~mm}$, depth; crucible for Ti ore: $\phi=25 \mathrm{~mm}$, I.D.; $d=120 \mathrm{~mm}$, depth), which were subsequently positioned in the quartz tube $(\phi=44.5 \mathrm{~mm}$, I.D.; $l=820 \mathrm{~mm}$, length), as shown in Fig. 4. As exceptional cases, in Exp. no. 130626, carbon was not used in the experiments in order to increase the $p_{\mathrm{O}_{2}}$ in the system, and in Exp. no. 130730, a mixture of $\mathrm{Ti}$ ore and carbon was used. After the samples were placed in the quartz tube, the tube was plugged by a Viton rubber plug. Afterward, liquid $\mathrm{TiCl}_{4}$ (Wako Pure Chemical Industries Ltd., purity $\geq 99.0 \%$ ) was transferred from the reagent bottle to a glass bottle filled with argon gas (Ar, purity $\geq 99.9995 \%$ ) in a glove bag purged with nitrogen gas $\left(\mathrm{N}_{2}\right.$, purity $\left.\geq 99.999 \%\right)$ to prevent the reaction between $\mathrm{TiCl}_{4}$ and the $\mathrm{H}_{2} \mathrm{O}$ present in air as much as possible.

After the samples and liquid $\mathrm{TiCl}_{4}$ were prepared, the quartz tube was evacuated thrice for $5 \mathrm{~min}$ each, and the tube was filled with Ar gas between the evacuations until the internal pressure reached $1 \mathrm{~atm}$. After the final filling (a)
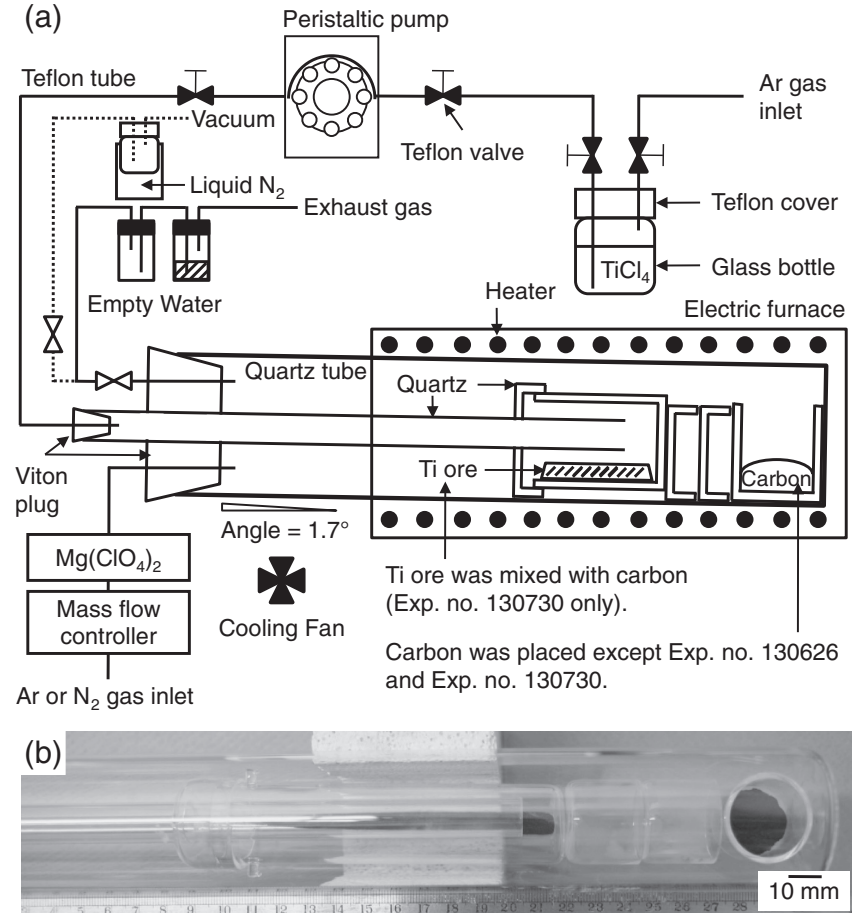

Fig. 4 (a) Schematic diagram of the experimental apparatus and (b) photograph taken before the experiments showing some of the samples placed in the quartz tube.

with Ar gas, Ar gas was flowed through the quartz tube at a controlled rate using a mass flow controller (MFC) while the internal pressure of the tube was maintained at $1 \mathrm{~atm}$. In all the procedures, $\mathrm{Ar}$ gas was supplied into the quartz tube through magnesium perchlorate $\left(\mathrm{Mg}\left(\mathrm{ClO}_{4}\right)_{2}\right.$, Kanto Chemical Co., Inc., purity $\geq 75 \%$ ) to remove the $\mathrm{H}_{2} \mathrm{O}$ in the Ar gas. 
Table 2 Analytical results for the feedstock used and residues obtained after experiments.

\begin{tabular}{|c|c|c|c|c|c|c|}
\hline \multirow{2}{*}{ Exp. no. } & \multirow{2}{*}{$\begin{array}{l}\text { Source country } \\
\text { for Ti ore }\end{array}$} & \multicolumn{5}{|c|}{ Concentration of element $i, C_{i}(\operatorname{mass} \%)^{* 1}$} \\
\hline & & $\mathrm{Ti}$ & $\mathrm{Fe}$ & $\mathrm{Mn}$ & $\mathrm{Si}$ & $\mathrm{Al}$ \\
\hline \multirow{3}{*}{$\begin{array}{l}\text { Feedstock }{ }^{* 2} \\
\text { (Initial) }\end{array}$} & Vietnam & 45.0 & 49.7 & 3.47 & 0.57 & 0.33 \\
\hline & Australia & 48.5 & 46.7 & 1.69 & 1.00 & 1.02 \\
\hline & China & 47.2 & 45.4 & 2.79 & 1.65 & 1.41 \\
\hline 130626 & Vietnam & 98.0 & 0.69 & 0.05 & 0.36 & N.D \\
\hline 130703 & Vietnam & 97.7 & 0.39 & 0.05 & 0.96 & N.D \\
\hline 130704 & Australia & 97.6 & 0.39 & 0.04 & 0.63 & N.D \\
\hline 130708 & China & 94.8 & 2.28 & 0.15 & 0.83 & N.D \\
\hline 130730 & Vietnam & 97.6 & 0.50 & 0.11 & 0.71 & N.D \\
\hline $\begin{array}{l}{ }^{* 1} \text { Determine } \\
\text { element }) . \\
\text { N.D Not } \\
(<0.01 \text { mass }\end{array}$ & \multicolumn{5}{|c|}{$\begin{array}{l}{ }^{* 1} \text { Determined by XRF analysis (excluding oxygen and other gaseous } \\
\text { element). }\end{array}$} & $\begin{array}{l}\text { seous } \\
\text { XRF }\end{array}$ \\
\hline
\end{tabular}

After these atmosphere control procedures, the quartz tube was placed in a horizontal furnace preheated up to $1100 \mathrm{~K}$ for $30 \mathrm{~min}$. The reaction temperature of $1100 \mathrm{~K}$ was chosen by considering the reduction of energy consumption and reaction kinetics for the production of $\mathrm{TiO}_{2}(s)$. The quartz tube was placed at an angle of $1.7^{\circ}$ relative to the horizontal axis of the horizontal furnace, and the front part of the quartz tube outside the furnace was cooled by a fan to promote effective $\mathrm{TiCl}_{4}$ circulation inside the quartz tube. After the quartz tube was heated for $30 \mathrm{~min}$ in the furnace, liquid $\mathrm{TiCl}_{4}$ (boiling temperature: $408 \mathrm{~K}$ ) was fed into the tube by a peristaltic pump (Cole-Parmer Instrument Co., MasterFlex L/S Digital Drive, 7523-70; PTFE Tubing Pump, 77390-00) at a flow rate of $0.163-0.192 \mathrm{~g} / \mathrm{min}$. A continuous flow of liquid $\mathrm{TiCl}_{4}$ into the quartz tube was used, except for in Exp. no. 130626. A $\mathrm{TiCl}_{4}$ feeding pattern including periodic breaks was examined in order to decrease the amount of $\mathrm{TiCl}_{4}$ discharged from the quartz tube without participating in the chlorination reaction. ${ }^{29)}$

In most cases, the quartz tube was instantly removed from the furnace after the reaction at a preset time and cooled down at room temperature. However, for Exp. no. 130730, evacuation using a diaphragm pump (As One Co., MAS-1) was performed $10 \mathrm{~min}$ prior to the removal of the quartz tube from the furnace until the quartz tube was cooled down. The aim of this step was to remove the exhaust gas remaining in the quartz tube. Afterward, the quartz tube was filled with Ar gas until the internal pressure reached $1 \mathrm{~atm}$, and Ar gas was flowed at room temperature while the internal pressure of the tube was maintained at $1 \mathrm{~atm}$.

Three methods were applied to collect the residues from the quartz tube after the experiments. In Exp. no. 130704, the quartz tube was placed in a furnace preheated up to $500 \mathrm{~K}$ for $4 \mathrm{~h}$ under a $\mathrm{N}_{2}$ gas atmosphere before the tube was taken out. Then, the quartz tube was filled with Ar gas until the internal pressure of the tube reached $1 \mathrm{~atm}$, and subsequently Ar gas was flowed through the tube at room temperature until the $\mathrm{TiCl}_{4}$ inside the tube was dried. The vapor pressure of $\mathrm{TiCl}_{4}$ (l) at $300 \mathrm{~K}$ is $0.02 \mathrm{~atm}$, which is sufficient for evaporation. ${ }^{28)}$

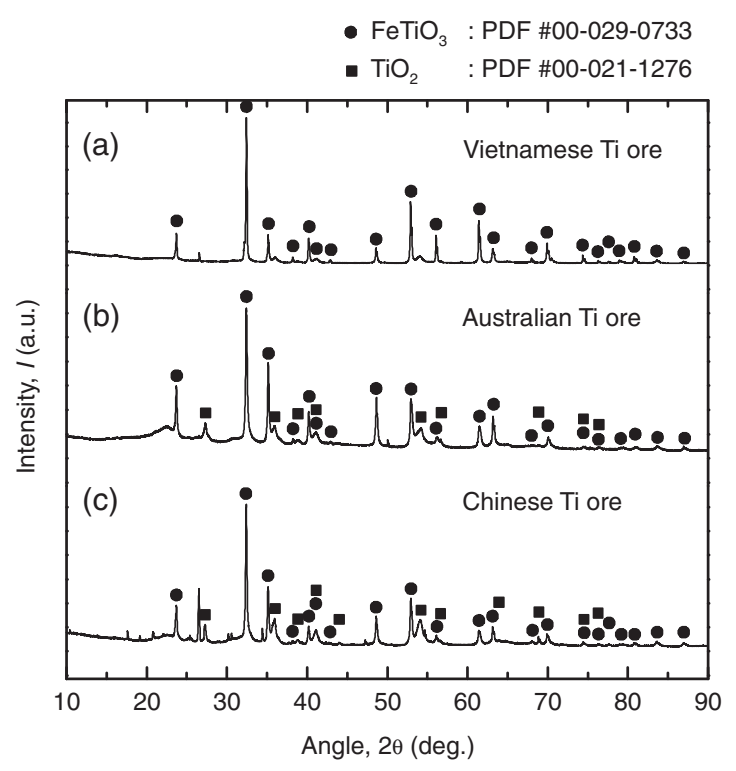

Fig. 5 Results of XRD analysis of the (a) Vietnamese, (b) Australian, and (c) Chinese Ti ores used in this study.

Therefore, the $\mathrm{TiCl}_{4}$ in the quartz tube could be dried by supplying Ar gas. In Exp. no. 130730, the Ar gas was flowed through the quartz tube at room temperature until the $\mathrm{TiCl}_{4}$ inside the tube was dried. For all the other experiments, a small amount of acetone was injected into the quartz tube through the outlet pipe while the Ar gas flow was maintained to remove $\mathrm{TiCl}_{4}$ from the front part of the tube. ${ }^{30)}$ After the residues were taken out of the quartz tube, they were dissolved in deionized water and sonicated for over one hour at room temperature.

The chemical compositions of the residues obtained after the experiments were analyzed using X-ray fluorescence spectroscopy (XRF: JEOL, JSX-3100RII). The crystalline phases were identified by X-ray diffraction (XRD: RIGAKU, RINT 2500, $\mathrm{Cu}-\mathrm{K} \alpha$ radiation), and the microstructures and compositions were analyzed by scanning electron microscopy/energy dispersive X-ray spectroscopy (SEM/ EDS: JEOL, JSM-6510LV).

\section{Results and Discussion}

Figure 5 shows the results of XRD analysis of the Vietnamese, Australian, and Chinese Ti ores used in this study. As shown in Fig. 5, the main crystalline phase in the Ti ores was $\mathrm{FeTiO}_{3}$. In addition, $\mathrm{TiO}_{2}$ was also identified depending on the types of $\mathrm{Ti}$ ores.

Figure 6 shows representative photographs of the lowtemperature part of the quartz reaction tube during and after the experiment. $\mathrm{TiCl}_{4}$ has a high vapor pressure even at room temperature, as mentioned before. Therefore, a certain amount of $\mathrm{TiCl}_{4}$ that did not react with Ti ore was discharged from the quartz tube during the experiments and then condensed in a liquid form in the middle of the outlet line. To minimize the loss of unreacted $\mathrm{TiCl}_{4}$, several methods were used to facilitate $\mathrm{TiCl}_{4}$ circulation in the quartz tube, such as the use of a cooling fan or setting the quartz tube at a small tilting angle. As a result, as shown in Fig. 6(a), 

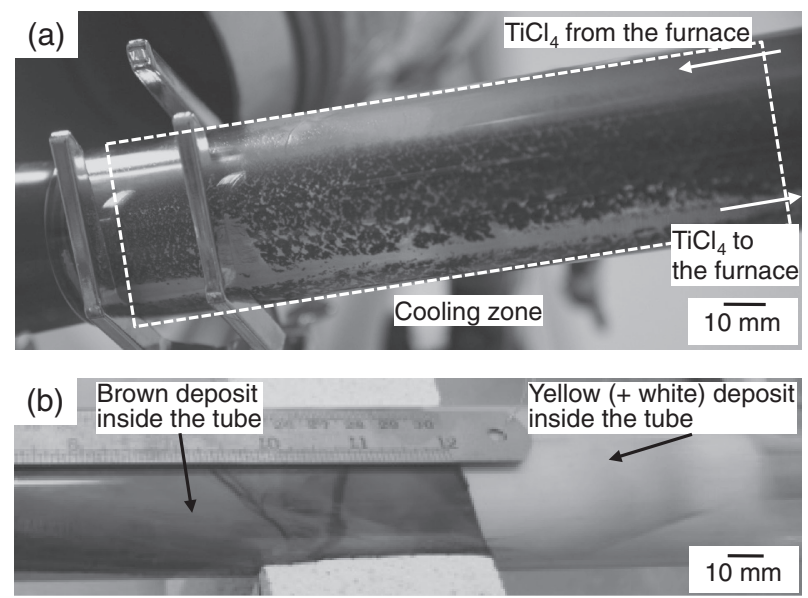

Fig. 6 Representative photographs of low-temperature part of the quartz tube (a) during the experiment (Exp. no. 130626) and (b) after the experiment (Exp. no. 130704).

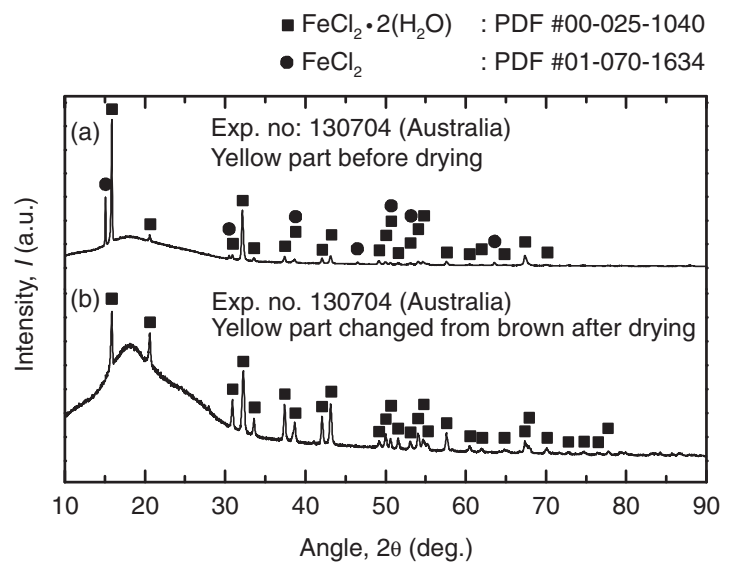

Fig. 7 Results of XRD analysis of the powders condensed in the lowtemperature part of the quartz tube (Exp. no. 130704): (a) yellow part before the quartz tube was dried and (b) yellow part changed from brown after the quartz tube was dried.

a certain amount of unreacted $\mathrm{TiCl}_{4}$ discharged from the reaction zone was cooled and condensed into a liquid in the cooling zone, and this liquid flowed back towards the reaction zone during the experiment because the horizontal quartz tube was slightly tilted.

After the experiments, yellow (and white) and brown deposits were generated inside the quartz tube, as shown in Fig. 6(b). The brown deposits became yellow after the quartz tube was dried. Therefore, it is supposed that the $\mathrm{TiCl}_{4}$ remaining in the low-temperature part of the quartz tube was evaporated and removed when Ar gas was flowed through the tube. Figure 7 shows the results of XRD analysis of the two different yellow deposits obtained after drying brown or yellow deposits in the quartz tube. As shown in Fig. 7, $\mathrm{FeCl}_{2}$ and $\mathrm{FeCl}_{2} \cdot 2\left(\mathrm{H}_{2} \mathrm{O}\right)$ were identified by the XRD analysis. Regarding the $\mathrm{H}_{2} \mathrm{O}$ in the $\mathrm{FeCl}_{2} \cdot 2\left(\mathrm{H}_{2} \mathrm{O}\right)$, it seems $\mathrm{H}_{2} \mathrm{O}$ in air had attached to $\mathrm{FeCl}_{2}$ when the Viton rubber plug was removed from the quartz tube in order to obtain the residues.

Figure 8 shows SEM images of the surface of a Ti ore particle obtained before and after the carbo-selective-
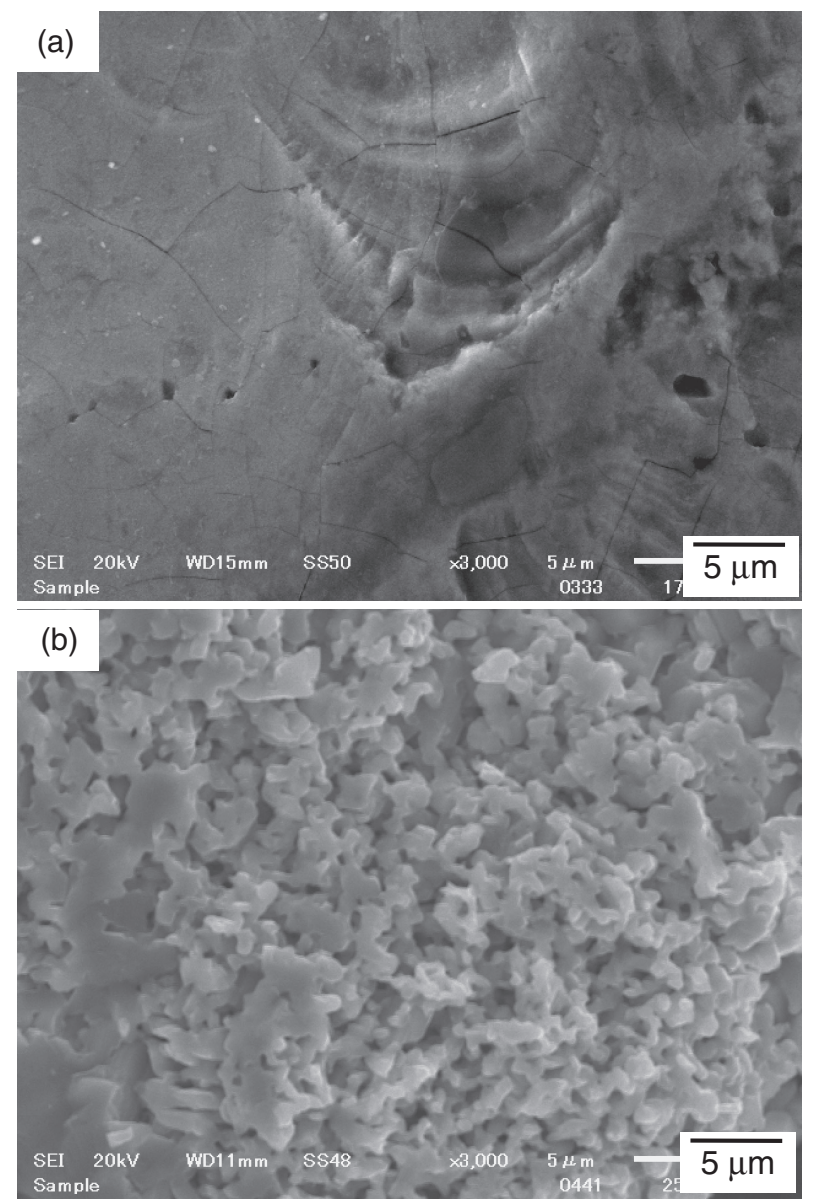

Fig. 8 SEM images of the surface of a Vietnamese Ti ore particle (a) before the experiment and (b) after the selective chlorination experiment (Exp. no. 130703).

chlorination experiment. As shown in Fig. 8, small pores were formed on the surfaces of the residues obtained after experiment. It is expected that the majority of the pores were formed by the evaporation of iron chloride. This is because the vapor pressure of $\mathrm{FeCl}_{2}$ generated by the reaction at $1100 \mathrm{~K}$ is high enough for the $\mathrm{FeCl}_{2}$ to evaporate, and the evaporated $\mathrm{FeCl}_{2}$ was condensed at the lowtemperature part of the quartz tube. Therefore, the authors concluded that the iron in the Ti ore was removed as $\mathrm{FeCl}_{2}$ $(l, g)$ by $\mathrm{TiCl}_{4}$ at $1100 \mathrm{~K}$ as expected from the thermodynamic analysis.

Table 2 summarizes the analytical results for the feedstock used and the residues obtained after the experiments. In addition, Fig. 9 shows the results of XRD analysis of the residues obtained after experiments when the Vietnamese $\mathrm{Ti}$ ore (Exp. no. 130703), Australian Ti ore (Exp. no. 130704), and Chinese $\mathrm{Ti}$ ore (Exp. no. 130708) were used as feedstock. As shown in Table 2 and Fig. 9, when the Vietnamese and Australian Ti ores were used as feedstock, the concentrations of $\mathrm{Ti}$ increased from 45 to 98 mass $\%$ and from 49 to 98 mass $\%$, respectively, after the selective removal of iron from the $\mathrm{Ti}$ ore. As a result, $98 \% \mathrm{TiO}_{2}$ was obtained in both cases. The purity of $\mathrm{TiO}_{2}$ was calculated by converting all the elements measured by XRF to their nominal simple oxides. In addition, when the Chinese $\mathrm{Ti}$ ore was used as feedstock, $95 \% \quad \mathrm{TiO}_{2}$ was obtained after the experiment. 


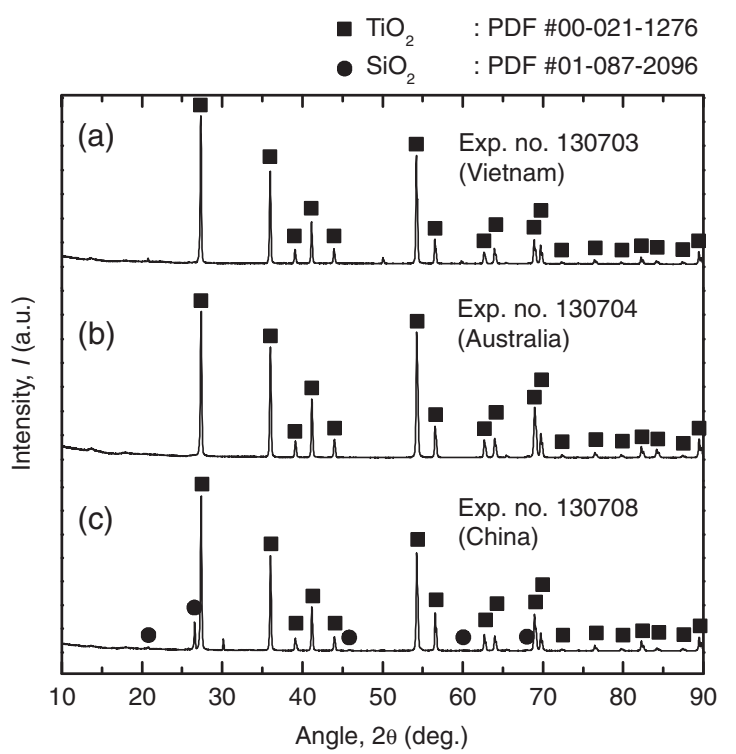

Fig. 9 Results of XRD analysis of the residues obtained after experiments when the (a) Vietnamese (Exp. no. 130703), (b) Australian (Exp. no. 130704), and (c) Chinese (Exp. no. 130708) Ti ores were used as feedstock.

Therefore, it can be claimed that various types of $\mathrm{Ti}$ ores can be upgraded to the $\mathrm{TiO}_{2}$ with a purity of above $95 \%$ by selectively removing iron directly from the ores in a single step through carbo-selective-chlorination.

As mentioned before, to increase the circulation of $\mathrm{TiCl}_{4}$ inside the quartz tube, two types of $\mathrm{TiCl}_{4}$ feeding patterns were examined: continuous feeding of $\mathrm{TiCl}_{4}$ and feeding of $\mathrm{TiCl}_{4}$ with periodic breaks. However, in the results from Exp. no. 130626 and Exp. no. 130703 shown in Table 2, even though different feeding patterns of $\mathrm{TiCl}_{4}$ were adopted, no significant difference in the $\mathrm{TiO}_{2}$ purity (98\% in both cases) was observed under the experimental conditions applied in this study.

As discussed regarding the thermodynamic analysis of the carbo-selective-chlorination method (see Fig. 3), the potential region of this study is considered to be the crosshatched region in which the oxygen chemical potential ranges from point $\mathrm{d} 1(\mathrm{C}(s) / \mathrm{CO}(g)$ eq.) to point e1 $(\mathrm{FeO}$ $(s) / \mathrm{Fe}_{3} \mathrm{O}_{4}(s)$ eq.) in Fig. 3. When carbon and $\mathrm{TiCl}_{4}$ exist in the reaction system, the potential of the system is located in the oxygen chemical potential ranges from point $\mathrm{d} 1$ to point $\mathrm{d} 2$ in the cross-hatched region in Fig. 3. The experimental conditions for Exp. no. 130626 and Exp. no. 130703 can be considered examples of two conditions: one in which the $p_{\mathrm{O}_{2}}$ is located in the range from the $\log p_{\mathrm{O}_{2}}$ value determined by the $\mathrm{Fe}(s) / \mathrm{FeO}(s)$ eq. to point $\mathrm{e} 1$, and another in which the $p_{\mathrm{O}_{2}}$ value is located in the range from point $\mathrm{d} 1$ to point $\mathrm{d} 2$. In both cases, the iron in the $\mathrm{Ti}$ ore was selectively removed, and $98 \% \mathrm{TiO}_{2}$ was obtained. Therefore, the authors claim that if the chemical potentials of oxygen and chlorine are located in the potential region for carbo-selective-chlorination shown in Fig. 3, iron can be selectively removed from $\mathrm{Ti}$ ore and a high-grade $\mathrm{TiO}_{2}$ can be obtained.

Ti ore contains several impurities besides iron, such as manganese $(\mathrm{Mn})$, aluminum $(\mathrm{Al})$, or silicon $(\mathrm{Si})$. Among these impurities, it was found that manganese oxide $(\mathrm{MnO})$ was also removed from $\mathrm{Ti}$ ore by the carbo-selectivechlorination, as shown in Table 2. The chemical reaction between $\mathrm{MnO}$ and $\mathrm{TiCl}_{4}$ is shown in eq. (3).

$$
\begin{gathered}
\mathrm{MnO}(s, \text { in the ore })+1 / 2 \mathrm{TiCl}_{4}(g) \\
=\mathrm{MnCl}_{2}(l)+1 / 2 \mathrm{TiO}_{2}(s) \\
\Delta G_{\mathrm{r}}^{\circ}=-98.9 \mathrm{~kJ} \text { at } 1100 \mathrm{~K}^{28)}
\end{gathered}
$$

The analytical results showed decreased concentrations of aluminum in the residues after experiments. However, in the case of aluminum, from a thermodynamic point of view, $\mathrm{Al}_{2} \mathrm{O}_{3}$ is difficult to remove with $\mathrm{TiCl}_{4}$, as shown in eq. (4). Therefore, further study is required to investigate the behavior of aluminum and other impurities in the $\mathrm{Ti}$ ore during the carbo-selective-chlorination process.

$$
\begin{gathered}
\mathrm{Al}_{2} \mathrm{O}_{3}(s, \text { in the ore })+3 / 2 \mathrm{TiCl}_{4}(g) \\
=2 \mathrm{AlCl}_{3}(g)+3 / 2 \mathrm{TiO}_{2}(s) \\
\Delta G^{\circ}{ }_{\mathrm{r}}=102.4 \mathrm{~kJ} \text { at } 1100 \mathrm{~K}^{28)}
\end{gathered}
$$

\section{Conclusions}

In order to selectively remove iron directly from low-grade titanium ore (e.g., $\mathrm{FeTiO}_{3}$ ), thermodynamic analysis considering the chemical potentials of oxygen and chlorine was conducted. Then, the suitable chemical potential region for carbo-selective-chlorination using $\mathrm{TiCl}_{4}$ as a chlorinating agent was investigated for the selective removal of iron from Ti ore to produce high-grade $\mathrm{TiO}_{2}$. When the selective chlorination experiments were conducted under $\mathrm{Ar}$ or $\mathrm{Ar}+\mathrm{C}$ atmospheres at $1100 \mathrm{~K}$ using low-grade Ti ores produced from Vietnam, Australia, and China as feedstock, the iron in the ores was selectively removed in the form of iron chloride $\left(\mathrm{FeCl}_{2}\right)$. As a result, $98 \% \mathrm{TiO}_{2}$ was produced directly from low-grade $\mathrm{Ti}$ ore containing $51 \% \mathrm{TiO}_{2}$ in a single step under certain conditions. Thus, the carbo-selective-chlorination investigated in this study is demonstrated to be a feasible process for upgrading low-grade titanium ore for the production of high-grade titanium dioxide.

\section{Acknowledgments}

The authors are grateful to Professors Kazuki Morita and Takeshi Yoshikawa, The University of Tokyo; Professor Tetsuya Uda, Kyoto University; Dr. Osamu Takeda, Tohoku University; and Messrs. Susumu Kosemura, Masanori Yamaguchi, and Yuichi Ono, Toho Titanium Co., Ltd. for their valuable discussions and the supply of samples throughout this study. Furthermore, the authors thank Dr. Katsuhiro Nose and Dr. Yu-ki Taninouchi for their valuable suggestions and technical assistance. This research was partly funded by a Grant-in-Aid for the Next Generation of WorldLeading Researchers (NEXT Program) for the Research Project for Development of Environmentally Sound Recycling Technology of Rare Metals. Jungshin Kang is grateful for the financial support provided by the MEM (Mechanical, Electrical and Materials Engineering) International Graduate Program from the Ministry of Education, Culture, Sports, Science and Technology (MEXT), Japan and the Grants for Excellent Graduate Schools, MEXT, Japan. 


\section{REFERENCES}

1) W. Kroll: Trans. Electrochem. Soc. 78 (1940) 35-47.

2) H. Zheng and T. H. Okabe: J. Alloy. Compd. 461 (2008) 459-466.

3) T. H. Okabe and J. Kang: The Latest Technological Trend of Rare Metals, Ed. by T. H. Okabe and K. Nose, (CMC Publishing Co., Ltd., Tokyo, Japan, 2012) pp. 83-94.

4) J. Kang and T. H. Okabe: Mater. Trans. 54 (2013) 1444-1453.

5) The Japan Titanium Society: Titan 61 (2013) 84.

6) T. H. Okabe and J. Kang: Molten Salts 56 (2013) 15-26.

7) R. G. Becher, R. G. Canning, B. A. Goodheart and S. Uusna: Proc. Aust. Inst. Min. Metall. 21 (1965) 21-44.

8) W. Hoecker: European Patent EP0612854, (1994).

9) J. H. Chen and L. W. Huntoon: United States Patent 4019898, (1977).

10) J. H. Chen: United States Patent 3967954, (1976).

11) J. H. Chen: United States Patent 3825419, (1974).

12) M. Guéguin and F. Cardarelli: Miner. Process. Extr. Metall. Rev. 28 (2007) 1-58

13) K. I. Rhee and H. Y. Sohn: Metall. Mater. Trans. B 21 (1990) 341-347.

14) S. Fukushima and E. Kimura: Titanium · Zirconium 23 (1975) 67-74.

15) E. Kimura, A. Fuwa and S. Fukushima: Nippon Kogyo Kaishi 95 (1979) 821-827.

16) A. Fuwa, E. Kimura and S. Fukushima: Metall. Mater. Trans. B 9 (1978) 643-652.
17) K. I. Rhee and H. Y. Sohn: Metall. Mater. Trans. B 21 (1990) 331-340.

18) K. I. Rhee and H. Y. Sohn: Metall. Mater. Trans. B 21 (1990) 321-330.

19) L. K. Doraiswamy, H. C. Bijawat and M. V. Kunte: Chem. Eng. Prog. 55 (1959) 80-88.

20) H. Zheng and T. H. Okabe: Proc. 16th Iketani Conf., Masuko Symposium, Ed. by S. Yamaguchi, (The 16th Iketani Conference Organizing Committee, 2006, Japan) pp. 1005-1010.

21) R. Matsuoka and T. H. Okabe: Proc. Symp. on Metallurgical Technology for Waste Minimization, (134th TMS Annual Meeting, 2005, San Francisco, United States) http://www.okabe.iis.u-tokyo.ac.jp/ japanese/for_students/parts/pdf/050218_TMS_proceedings_matsuoka.pdf.

22) J. Kang and T. H. Okabe: Metall. Mater. Trans. B 44 (2013) 516527.

23) D. F. Othmer: United States Patent 3859077, (1975).

24) D. F. Othmer and R. Nowak: AlChE J. 18 (1972) 217-220.

25) D. F. Othmer: United States Patent 3989510, (1976).

26) G. Holland and R. Nowak: United States Patent 4288411, (1981).

27) W. E. Dunn: United States Patent 3865920, (1975).

28) I. Barin: Thermochemical Data of Pure Substances, 3rd ed., (VCH Verlagsgesellschaft mbH, Weinheim, Germany, 1995).

29) O. Takeda: Doctoral thesis, The University of Tokyo, (2006).

30) Y. Wu, H. Liu, B. Xu, Z. Zhang and D. Su: Inorg. Chem. 46 (2007) 5093-5099.

31) N. Nakamura: Molten Salts 56 (2013) 121-124 (in Japanese). 